FERREIRA, C.G.T., GAMALEIRA, J.S. e AHID, S.M.M. Ectoparasitos em caprinos no Município de Parelhas, Rio Grande do Norte, Brasil. PUBVET, Londrina, V. 5, N. 18, Ed. 165, Art. 1113, 2011.

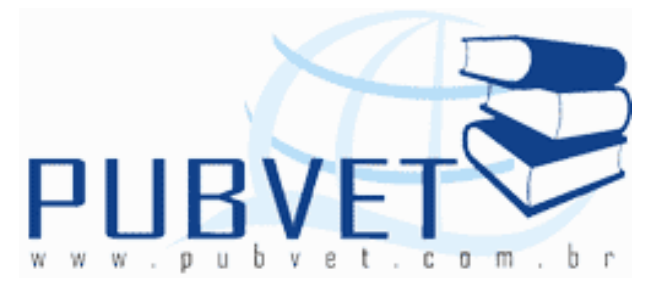

PUBVET, Publicações em Medicina Veterinária e Zootecnia.

\title{
Ectoparasitos em caprinos no Município de Parelhas, Rio Grande do Norte, Brasil
}

\section{Caroline Gracielle Torres Ferreira ${ }^{1}$, Jucélio da Silva Gameleira ${ }^{2}$, Silvia Maria Mendes Ahid $^{3}$}

${ }^{1}$ Médica Veterinária. e-mail: caroline-torres@hotmail.com

${ }^{2}$ Discente de Medicina Veterinária, Universidade Federal Rural do Semi-Árido (UFERSA). e-mail: jucelio gameleira@hotmail.com

${ }^{3}$ Docente do Departamento de Ciências Animal, coordenadora do Laboratório de Parasitologia Animal da UFERSA. e-mail: ahid@ufersa.edu.br

\section{Resumo}

As ectoparasitoses acarretam perdas econômicas, seja devido à mortalidade decorrente de altas infestações, ou indiretamente, por meio da irritação causada nos animais, levando-os a queda da produtividade e predisposição a infecções secundárias. Este estudo teve como objetivo o levantamento dos ectoparasitos que acometem caprinos do município de Parelhas, Rio Grande do Norte. Foram inspecionados 300 caprinos em fevereiro de 2009 em propriedades de pequenos e médios criadores de criação extensiva. Os espécimes coletados foram acondicionados em frascos, contendo álcool a 70\% para posterior identificação. Dos 300 caprinos examinados, 250 (83,3\%\%) apresentaram infestação por Damalinia caprae, sendo 70 (28\%) animais jovens e $180(72 \%)$ animais adultos. Os resultados indicaram que os animais 
FERREIRA, C.G.T., GAMALEIRA, J.S. e AHID, S.M.M. Ectoparasitos em caprinos no Município de Parelhas, Rio Grande do Norte, Brasil. PUBVET, Londrina, V. 5, N. 18, Ed. 165, Art. 1113, 2011.

estudados são importantes hospedeiros de ectoparasitos, confirmando-se a presença disseminada deste piolho, corroborando com trabalhos em todo território nacional.

Palavras-chave: Phthiraptera, caprinos, semi árido.

\title{
Ectoparasites on goats in the city of Parelhas, Rio Grande do Norte, Brazil
}

\begin{abstract}
The infestation cause economic losses, either due to high mortality due to infestation, or indirectly, caused by irritation in animals, causing them to fall in productivity and susceptibility to secondary infections. This study aimed to survey of ectoparasites that infect goats in the city of Parelhas, Rio Grande do Norte. 300 goats were inspected in February 2009 on the properties of small and medium farmers of pasture. The specimens were placed in vials containing alcohol $70^{\circ} \mathrm{GL}$ for further identification. Of the 300 goats examined, 250 (83.3\%) had Damalinia caprae infestation, 70 (28\%) and 180 young animals $(72 \%)$ adult animals. The results indicated that the animals are important hosts for ectoparasites, confirming the widespread presence of this louse, corroborating work nationwide.
\end{abstract}

Keywords: Phthiraptera, goats, semi arid.

\section{INTRODUÇÃO}

O Nordeste brasileiro concentra $90 \%$ do plantel nacional de caprinos, nesta região a caprinocultura assume um papel relevante na economia do país por apresentar o maior rebanho e pelo aproveitamento dos seus produtos e subprodutos na produção familiar, despertando desta forma, grande interesse na política econômica do país.

Dentre as doenças que afetam os caprinos podem-se destacar as ectoparasitoses, que acarretam perdas econômicas, seja devido à mortalidade 
FERREIRA, C.G.T., GAMALEIRA, J.S. e AHID, S.M.M. Ectoparasitos em caprinos no Município de Parelhas, Rio Grande do Norte, Brasil. PUBVET, Londrina, V. 5, N. 18, Ed. 165, Art. 1113, 2011.

decorrente de altas infestações, ou indiretamente, por meio da irritação causada nos animais, levando-os a queda da produtividade e predisposição a infecções secundárias (Maciel et al., 2006).

Dentro desse contexto, a pediculose causada por piolhos mastigadores é a ectoparasitose mais freqüente, que embora se tenha progressos tecnológicos no seu controle, vêm aumentando o risco de comprometimento da qualidade do couro, marcados pela intensa descamação da pele e possibilidade de parasitismo misto, pelos tipos hematófagos (Santos et al., 2006a).

Considerando a importância do conhecimento sobre os ectoparasitos que acometem caprinos, aliado a possibilidade de variação na freqüência e no número de espécies de uma região para outra motivaram o desenvolvimento do presente trabalho, o qual objetiva identificar os ectoparasitos que acometem os caprinos no município de Parelhas, Rio Grande do Norte, Brasil.

\section{MATERIAL E MÉTODOS}

O Rio Grande do Norte possui 401.510 caprinos, destes 0,8\% caprinos encontram-se no município de Parelhas (06 $41^{\prime} 16,8^{\prime \prime} \mathrm{S} 36^{\circ} 39^{\prime} 28,8^{\prime \prime}$ W) situase na mesorregião Central Potiguar e na microrregião Seridó Oriental, abrangendo uma área de $523 \mathrm{~km}^{2}$, altitude média de $266 \mathrm{~m}$, possui clima muito quente e semi-árido com temperatura média anual $27,5^{\circ} \mathrm{C}, 2.400 \mathrm{~h}$. de insolação, pluviométrica anual 568,2 $\mathrm{mm}$ e umidade relativa média anual de $64 \%$.

Os animais examinados eram provenientes de propriedades de pequenos e médios criadores de criação extensiva. Foram examinados 300 caprinos através de observações manuais aleatórias em 10\% desses animais, independente do sexo. Os espécimes coletados foram acondicionados em frascos individuais, por hospedeiro amostrado, contendo álcool a $70^{\circ} \mathrm{GL}$ como líquido conservador. No laboratório de Parasitologia Animal da Universidade Federal Rural do Semi-Árido (UFERSA) foi realizada a identificação com auxílio de estereomicroscópio, utilizando-se chave dicotômica, segundo a bibliografia 
FERREIRA, C.G.T., GAMALEIRA, J.S. e AHID, S.M.M. Ectoparasitos em caprinos no Município de Parelhas, Rio Grande do Norte, Brasil. PUBVET, Londrina, V. 5, N. 18, Ed. 165, Art. 1113, 2011.

especializada.

\section{RESULTADOS E DISCUSSÃO}

Dos 300 caprinos examinados, 250 (83,3\%\%) apresentaram infestação por Damalinia caprae, sendo $70(28 \%)$ animais jovens e $180(72 \%)$ animais adultos. Conforme os resultados obtidos observou-se parasitismo por $D$. caprae em caprinos, concordando com os achados no Ceará, na Paraíba, no Rio Grande do Sul, no Rio de Janeiro e em outros municípios do Rio Grande do Norte ao estudarem os aspectos da pediculose em caprinos. Entretanto, Santos et al. (2004a) não detectaram esta espécie de piolhos quando amostraram caprinos da região da Baixada Maranhense, divergindo dos resultados aqui apresentados.

Souza et al. (2001) ressaltaram que apesar dos danos causados pelo $D$. caprae, poucos são os estudos realizados, sobre essa espécie, na região Nordeste, demonstrando com isso a falta de interesse técnico-científico na exploração desta enfermidade. Santos e Faccini (1996) num estudo seccional em caprinos, de sexos e idades diferentes, na região semi-árida da Paraíba, constataram uma infestação de $72,3 \%$ por $D$. caprae, e todas as propriedades estavam infestadas com prevalência de 40 a 100\%. Neste sentido, as fêmeas caprinas apresentaram maior positividade do que os machos nas faixas etárias estudadas, principalmente na faixa etária acima de um ano, demonstrando resultados similares aos achados do presente estudo.

Ao exame clínico dos caprinos parasitados por D. caprae em ParelhasRN, os animais apresentaram inquietação e prurido corroborando com os sinais clínicos observados em outros estudos (Bezerra et al., 2007). As ectoparasitoses são causas freqüentes de prejuízos econômicos a ovinocaprinocultura, pois ocasionam aos animais stress, irritação, diminuição do apetite, diminuição da produção e da produtividade, além da desvalorização na comercialização da pele.

Pesquisas realizadas sobre os aspectos epidemiológicos da caprinocultura 
FERREIRA, C.G.T., GAMALEIRA, J.S. e AHID, S.M.M. Ectoparasitos em caprinos no Município de Parelhas, Rio Grande do Norte, Brasil. PUBVET, Londrina, V. 5, N. 18, Ed. 165, Art. 1113, 2011.

no Brasil demonstram que as ectoparasitoses estão entre os problemas sanitários mais freqüentes, embora seu percentual de ocorrência seja variável com a região estudada (Bezerra et al., 2007). Considerando a importância desta informação para o comércio das peles e couro destes animais deve-se tomar medidas de prevenção e controle para estes ectoparasitos.

\section{CONCLUSÕES}

O conhecimento dos ectoparasitos que acometem os caprinos no município de Parelhas-RN é extremamente importante para a formulação de programas adequados de manejo e controle dos pequenos ruminantes do semi-árido nordestino.

\section{REFERENCIAS}

BEZERRA, A. C. D. S. et al. 2007. Prevalência de ectoparasitos em caprinos e ovinos do município de Mossoró, Rio Grande do Norte, Acta Veterinária Brasílica, 1 (2): 68.

MACIEL, F. C. et al. 2006. Manejo sanitário de caprinos e ovinos. In: LIMA, G. F. C et al. (Org) Criação Familiar de Caprinos e Ovinos no Rio Grande do Norte: orientações para viabilização do negócio rural. Natal: EMATER/EMPARN/EMBRAPA caprinos, p. 391-426.

SANTOS, A. C. G. \& FACCINI, J. L. H. 1996. Estudo seccional da piolheira caprina causada por Damalinia caprae (GURLT, 1843) (Thichodectidae: Mallophaga) na região do semi-árido do estado da Paraíba. Revista Brasileira de Parasitologia Veterinária, 5: 43-46.

SANTOS, A. C. G. et al. 2004a. Prevalência de artrópodes ectoparasitos em caprinos (Capra hircus L.) naturalmente infestados da Baixada Maranhense, Brasil. In: CONGRESSO BRASILEIRO DE MEDICINA VETERINÁRIA, 31, São Luís, 2004, Anais... São Luís.

SANTOS, S. B. et al. 2006a. Infestação por Linognathus africanus (KELLOGG e PAINE, 1911) (Linognathidae) e Bovicola caprae (ERWING, 1936) (Trichodectidae) em rebanho caprino no estado do Rio de Janeiro, Brasil. Revista Brasileira de Parasitologia Veterinária, 15 (1): 41-43.

SOUZA, M. F. et al. 2001. Levantamento de ectoparasitos em caprinos (Capra hircus L.) no sertão paraibano. In: SEMANA DA MEDICINA VETERINÁRIA DA ESAM, 3, Mossoró-RN, 2001. Anais... Mossoró. 